\title{
Editorial: Lisbon 2008 special issue
}

\author{
Noel T. Clemens $\cdot$ Cam Tropea
}

Published online: 2 October 2009

(C) Springer-Verlag 2009

Experiments in Fluids is pleased to present, for the fourth time, a special issue arising from the International Symposia on Applications of Laser Techniques to Fluid Mechanics, held biennially in Lisbon since 1982. The 14th Symposium was held from July 7 th to 10th, 2008. This special issue comprises 24 articles presented at the Symposium, preselected by the organizing committee of the meeting, and subsequently submitted to the normal review process of Experiments in Fluids. The editors are very grateful to the organizing committee for this assistance, and we feel that these articles, together with the proceedings of the conference, represent an excellent overview of the state-of-the-art of laser techniques and applications in fluid mechanics.

Our thanks go to the authors and referees for keeping to a strict time schedule and, of course, to the Springer-Verlag staff, in particular Mr. Kalithasan Natarajan, who coordinated the final production of the issue.

At this opportunity, we would like to draw our readers' attention to a number of changes at Experiments in Fluids. The first concerns our editorial staff. Prof. Don Rockwell, Editor-in-Chief since 1994, has stepped down in Feb. 2009 and Prof. Noel Clemens from the University of Texas at Austin has taken over this position as Co-Editor-in-Chief with Prof. Cam Tropea from the Technische Universität Darmstadt. Experiments in Fluids has benefitted greatly from the leadership and judgement of Prof. Rockwell, an appropriate tribute to his service at Experiments in Fluids is forthcoming.

Furthermore, Experiments in Fluids has maintained its vigorous program of special issues, both those arising from selected conferences, and topical issues coordinated by guest editors. Our readers are invited to examine our last special issue on the topic of Animal Locomotion: The Physics of Flying (Vol. 46, No. 5, May 2009). The editorial staff is committed to continuing this program of issues, and we look forward to an increased authorship and readership as we explore specific areas of fluid mechanics in more detail.

Finally, we would like to note that our efforts over the past years to accelerate the review process at Experiments in Fluids have been very successful, thanks to the efforts of our referees. We now have a submission-to-first-decision time median of under 60 days. Our impact factor has risen continually over this same period as has the number of pages per volume, now $\sim 2,400$ per year. The editors would like to thank our readers for their sustained support of Experiments in Fluids, and we hope you enjoy this special issue from the Lisbon Symposium.

\footnotetext{
N. T. Clemens

Department of Aerospace Engineering and Engineering

Mechanics, The University of Texas at Austin,

1, University Station, C0600, Austin, TX 78712, USA

e-mail: clemens@mail.utexas.edu

C. Tropea $(\bowtie)$

Fachgebiet Strömungslehre und Aerodynamik Technische

Universität, Darmstadt Petersenstr. 30,

64287 Darmstadt, Germany

e-mail: ctropea@sla.tu-darmstadt.de
} 